NASA Technical Memorandum 102554

SAE Paper No. 901033

$P=23$

\title{
Flow Studies in Close-Coupled Ventral Nozzles for STOVL Aircraft
}

Jack G. McArdle

National Aeronautics and Space Administration

Lewis Research Center

Cleveland, Ohio

and

C. Frederic Smith

Sverdrup Technology, Inc.

NASA Lewis Research Center Group

Cleveland, Ohio

Prepared for the

Aerospace Atlantic Conference

sponsored by the Society of Automotive Engineers

Dayton, Ohio, April 23-26, 1990

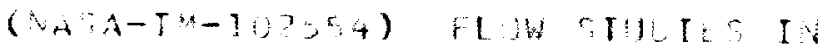

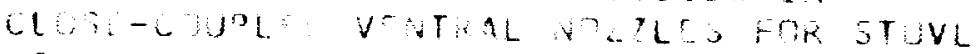

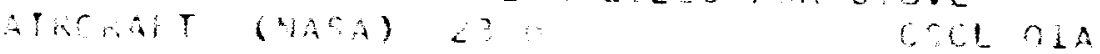

$$
\begin{aligned}
& 1472-20+34
\end{aligned}
$$




\title{
FLOW STUDIES IN CLOSE-COUPLED VENTRAL NOZZLES FOR STOVL AIRCRAFT
}

\author{
Jack G. McArdle \\ National Aeronautics and Space Administration \\ Lewis Research Center \\ Cleveland, Ohio 44135
}

and

C. Frederic Smith

Sverdrup Technology, Inc.

NASA Lewis Research Center Group

Cleveland, Ohio 44135

\section{SUMMARY}

Flow in a generic ventral nozzle system was studied experimentally and analytically with the PARC3D computational fluid dynamics program (a full Navier-Stokes equations solver) in order to evaluate the program's ability to predict system performance and internal flow patterns. A generic model of a tailpipe with a rectangular ventral nozzle, about one-third of full size, was tested with unheated air at steady-state pressure ratios up to 4.0 . The end of the tailpipe was closed to simulate a blocked exhaust nozzle. Measurements showed about $5 \frac{1}{2}$-percent flow-turning loss and reasonable nozzle performance coefficients. The flow turned more than the designed $90^{\circ}$, causing an aftward axial component in the total thrust. Flow behavior into and through the ventral duct is discussed and illustrated with paint streak flow visualization photographs. PARC3D graphic images are shown for comparison with the experiment photographs. The program successfully predicted internal flow patterns; it also computed thrust and discharge coefficients within 1 percent of measured values.

\section{INTRODUCTION}

Improved short takeoff and vertical landing (STOVL) aircraft, such as those shown in artists' sketches in figure 1 , are planned for possible future development. For these aircraft the same propulsion system will provide power for lift and hover as well as for supersonic horizontal flight. The propulsion system must have engines with high thrust to weight ratio, efficient gas ducting and thrusters, large, reliable valves and seals, and integrated engine and flight controis. To develop the required technology for aircraft of this type, the NASA Lewis Research Center is conducting important programs in mission analysis, integrated controls, lift thrusters, and hot gas reingestion in hover flight.

When the STOVL propulsion system is operating in the 1 ift mode, the rear jet nozzle will be blocked, and valves will be opened to duct engine exhaust gases to two or more thrusters directed downward. In many proposed configurations one of the lift thrusters will be a ventral nozzle. A typical arrangement is sketched in figure 2. The ventral nozzle draws mixed core and fan gases from the engine tailpipe through a valve and opening having no inlet turning vanes. Close coupling is necessary because the valve and the nozzle 
must be wholly contained within the fuselage. The ventral nozzle also may be vectored to provide trim or pitch control.

In an ongoing Lewis program ventral nozzle performance is being studied experimentally and analytically. A generic model tailpipe with a single large rectangular ventral nozzle, about one-third of full size, was built and was tested with unheated air. A blind flange at the end of the tailpipe simulated a blocked exhaust nozzle. Analytical performance of the same tailplpe/ventral nozzle configuration was modeled and studied with a computational fluid dynamics (CFD) code called PARC3D on a Cray Y-MP computer. A block version of PARC3D was used to simplify construction of the computational grid and to reduce the computer requirements for a fairly complex geometry. In this approach one computational grid block was used to represent the tailpipe and another to represent the ventral duct and nozzle.

The major objectives of the work reported here in were to expand understanding of ventral flow turning by appropriate tests, and to evaluate the ability of the chosen computational grid and CFD code to predict the experimental performance. The results are shown in performance plots for steady-state ratios of tailpipe to ambient pressure up to 4.0 , internal paint streak flow visualization photographs, and CFD graphic images for direct comparison with the experiment photographs.

\section{APPARATUS AND INSTRUMENTATION}

\section{Test Stand}

The model was tested at the Powered Lift Facility (PLF) at Lewis. The PLF is a unique outdoor stand designed to measure simultaneous axial (thrust), $11 \mathrm{ft}$ (pitch), and side (yaw) forces up to $2500016(110 \mathrm{kN}$ ). The stand was supplied with unheated alr from the central system at 150-psi (1000-kPa) pressure. Alrflow was controlled by a valve in the facility inlet line. Flow rate was measured with an ASME long-radius nozzle. The model mounted on the PLF stand is shown in figure 3 . The model was mounted with the ventral nozzle discharging upward for operational convenience.

Mode 1

A sketch of the model tallpipe and ventral nozzle is shown in figure 4 . A simple, uncomplicated design was chosen in order to make the CFD computational grid easy and accurate. The tailpipe was $13.5 \mathrm{in.}(34.3 \mathrm{~cm})$ in diameter, which is about one-third the size of many current military engines. The model was connected to the $24-i n$. $(61-\mathrm{cm})$ diameter facility mounting flange through a conical-plus-cylindrical transition section. This section contained two honeycomb flow straighteners and one fine-mesh screen, just ahead of the model. designed to provide uniform inflow. The screen was 14 mesh by 0.009 -in. $(0.23-\mathrm{mm})$ wire, and on the basis of results reported in reference 1, was relied on to reduce free-stream turbulence intensity to less than $1 / 2$ percent. In addition, a toothed metal strip, shown in figure 5 , protruded 0.06 in. ( $1.5 \mathrm{~mm}$ ) from the wall to ensure that the inflow boundary layer was turbulent. A blind flange was located two tailpipe diameters downstream of the ventral 
opening to simulate a blocked exhaust nozzle. The rectangular convergent ventral nozzle was mounted on a duct 0.89 tallpipe diameter long (measured from the tailpipe centerline). The intersecting edges of the ventral duct and tallpipe, at the ventral cutout, were not rounded.

An optional flow visualization plate, $0.06 \mathrm{in}$. (1.5 mm) thick, could be mounted on the vertical centerline (a plane of symmetry) of the model over the ventral opening. The plate extended one tailpipe diameter downstream of the opening to capture flow patterns in the tailpipe. The plate was not installed for performance tests or flow visualization photographs of the tailpipe and ventral duct walls.

\section{Instrumentation}

The model instrumentation stations are shown in figure 4 . Tailpipe pressure was measured with five total-pressure tubes on each of four equally spaced rakes at station 5 . Ventral nozzle inlet pressure was measured with 24 totalpressure tubes arranged uniformly in the duct at station 6 . The wall pressure at several locations on the model was measured with static-pressure taps. Ventral nozzle exit flow conditions were measured by probes, sketched in figure 6 , driven across the nozzle just downstream of the exit plane by an electric actuator. For one test the three-tipped probe was used to map the pitot-pressure distribution. For another test the calibrated conical probe was used to measure total pressure as well as flow angles, relative to the probe tip, as functions of the pressures measured at each of the five ports. Airflow, forces, air temperature, and amblent conditions were measured by facility instrumentation systems using calibrated load cells and other conventional transducers.

\section{PROCEDURE}

\section{Performance Tests}

After force system tares had been obtained, steady-state thrust and airflow performance were measured at several ratios of talipipe to ambient pressure (PR5) up to 4.0. The data were recorded on the central laboratory system and batch processed on a mainframe computer.

\section{Exit Surveys}

The flow-angle probe and total-pressure rake data were obtained at selected locations in the exit flow (station $6 B$ ) at PR5 $=3$. The data were processed along with the performance test data.

\section{Flow Visualization}

After the optional flow visualization plate has been installed, dabs of thick oily paint were laid on the plate with a syringe in a grid-like pattern. In order to minimize transient flow effects, airflow was started quickly, held at $P R 5=3$ for $1 \mathrm{~min}$, then quickly shut down. Flow caused the paint to run along streamlines, and the resulting streaks provided a clear picture of the 
flow pattern. A similar procedure was followed without the plate installed to obtain flow visualization photographs at the ventral duct walls.

\section{COMPUTATIONAL FLUID DYNAMICS}

A major objective in these studies was to evaluate the ability of a chosen computational grid and CFD code to predict the internal flow patterns and overall performance of a ventral nozzle system. To this end, the PARC 30 code was chosen from among several candidates, and the same tallplpe/ventral nozzle configuration used for the experimental work was modeled as described in the following paragraphs. (A more detalled discussion of the CFD code, procedures, and computational results is given in reference 2.)

\section{Computational Grid}

Because the experimental configuration had a geometric plane of symmetry, only one of the symmetric halves was modeled. A single contiguous computational grid would have been very difficult to use to model both the tailpipe and the ventral system because they are normal to each other. Therefore, the grid model was divided into two blocks. The tallpipe made up one block, which was modeled by using an 0-grid. The O-grid consisted of concentric circles parallel to the talipipe surface and radial lines perpendicular to the surface. The ventral ducts and nozzle made up the other block and were modeled by using an $\mathrm{H}$-grid. The $\mathrm{H}$-grid consisted of lines parallel and perpendicular to the walls. This approach provided body-conforming grids for each block. A "wire" diagram of the grid model is shown in figure 7; a photograph of the experimental model is shown for comparison.

\section{PARC3D Code}

The PARC3D code was originally developed at the NASA Ames Research Center to analyze external flows. It solves the three-dimensional, compressible-flow Navier-Stokes equations and includes a turbulence model. The code later was modified at the U.S. Alr Force Arnold Engineering Development Center for use

with internal flows. Trllinear interpolation was used to exchange computational information between the two modeling blocks. The code was run on the Cray Y-MP computer with $101 \times 51 \times 51$ grid points per block.

\section{RESULTS AND DISCUSSION}

The results are presented in terms of the ratio of tailpipe to ambient pressure (PR5) unless otherwise stated. For jet engine applications this pressure ratio must be held constant during ventral system use to keep the engine running at the same operating point.

\section{Ventral System Performance}

The gas stream loses energy in turning from the tailpipe into the ventral duct, resulting in decreased average total pressure. For STOVL aircraft the 
flow-turning loss can limit the maximum available ventral thrust during hover flight. The loss measured in the model tested, shown in figure 8 , was about $5 \frac{1}{2}$ percent when the tailpipe pressure ratio was greater than 2 . The loss computed by the PARC 30 program at PR5 $=2.96$ was only slightly higher. This magnitude should be typical of ventral system designs of this general type and size. Turning vanes or a rounded shape at the ventral inlet could reduce the loss, but might be difficult to package in a small space along with a shutoff valve and other hardware needed at the tallpipe opening. The data in figure 8 show that the loss is less at lower tailpipe pressure ratios. This trend implies that flow-turning loss is dependent on tailpipe velocity or Mach number: therefore, the loss should be lower in other similar configurations with smaller ventral nozzles.

Both the measured and analytical system performance is given in figure 9. For this figure the coefficients are defined as follows:

(1) Discharge coefficient: the measured flow rate divided by the ideal flow rate at the same inlet conditions and pressure ratio

(2) Total thrust coefficient: the measured total thrust divided by the ideal thrust produced by the measured flow at the same inlet conditions and pressure ratio

For the ventral system tested the discharge and thrust coefficients based on tailpipe conditions, shown by the open symbols in figures $9(a)$ and (b), are lower than usual for a simple conical nozzle, but this effect is due to the flow-turning loss. The coefficients rise to more normal levels when computed in the conventional manner, by using the averaged nozzle inlet total pressure ratio (PR6) as shown by the solid symbols. The PARC30 results and the experimental data are in excellent agreement. Both the measured and CFD-predicted forces show a negative thrust component, although the ventral nozzle axis was normal to the tailpipe centerline. This force is interpreted to mean that the jet had effectively turned more than $90^{\circ}$, as plotted in figure $9(c)$. The axial force measured 7 to 10 percent of the ventral nozzle total thrust (fig. $9(d))$; the PARC3D-computed force was 7 percent. In a STOVL aircraft the axial force would tend to accelerate the craft backward but could be overcome by vectoring the ventral nozzle or by opening some other thruster to produce a counteracting force.

\section{Flow Behavior}

In this discussion the words "upstream" and "front" are used interchangeably to refer to the forward wall of a ventral system installed in an aircraft as 11 lustrated in figure 2. In like manner, the words "downstream" and "rear" are used to refer to the aft wall. The results presented here are for a steady-state tailpipe pressure ratio, PR5 $=3$. The Mach number at station 5 measured 0.33 on the ventral side of the tailpipe and 0.27 on the opposite side. The difference was mainly due to a slight wall-pressure gradient. Other studies (refs. 2 to 4 ) have shown that a circumferential static-pressure gradient induced by the ventral opening does not persist far upstream and therefore would not cause problems related to turbine backpressure unless the ventral opening was located very close to the turbine.

Flow entering ventral duct. - In order to understand the manner in which 
flow turned from the tallpipe into the ventral opening, a test was made with the optional flow visualization plate installed as lliustrated in figure 4. The paint streaks resulting from this test, along with the velocity field computed with the PARC 30 code on the model plane of symmetry, are shown in figure 10. The paint streaks on the plate show that the flow did not turn sharply but rather split so that some of the flow made a smooth turn into the opening while some impacted the tallpipe wall to form a stagnation point slightly downstream of the opening. The impacted flow then split, with some flowing back into the ventral opening and some flowing farther into the tailpipe. In the tallpipe it circulated in a clockwlse direction and returned upstream along the wall opposite the ventral opening. The PARC3D results give the same general flow patterns and further show that the recirculating flow was moving along almost all the tailpipe surface at fairly low velocity. The wall flow could affect the cooling-air requirements for ventral systems in STOVL aircraft. The velocity vectors indicate that in the ventral duct the flow was separated from the upstream wall. The separated region was confirmed by measured wall pressures, which were lowest on the upstream wall. The flow continued to turn as it flowed through the duct. Continued turning suggests that the flow condition at the ventral nozzle inlet could be influenced by the length and shape of the duct, which, in turn, would affect the total performance of the ventral system.

Although the flow patterns have been described in two-dimensional terms, in fact the flow was highly three dimensional and many secondary and vortexlike flows existed, as discussed in the next section.

Flow along ventral duct walls. - For another flow visualization test the optional plate on the talipipe centerline was removed, and dabs of thick oily paint were laid on the ventral duct and nozzle walls. The next several figures show paint streak photographs from this test and corresponding particle trajectories computed by the PARC30 code. A particle trajectory is the path that a massless particle would take as it flowed through the ventral system. Although trajectories were computed only for one of the symmetric halves, in the following discussion a mirror image of each trajectory is assumed to exist in the other half. The mirror image is included in the figures to assist in comparing the experimental and analytical results. The paint streaks and particle trajectories obtained on the front ventral wall are shown in figure 11 . Both show that the separated region consisted of twin counterrotating vortices that drew flow from the outer corners and returned it to the tailpipe near the centerline. Static pressures measured on the forward wall were low, indicating highvelocity flow. A particle trajectory plot of the flow from the tailpipe wall (fig. 12) illustrates how flow caught in one of these vortices moved toward the ventral nozzle exit.

Both the paint streaks and the particle trajectories on the side walls (fig. 13) show that the air flowed out of the ventral duct and toward the vortices at the upstream wall. In the front corners the air turned along the wall toward the nozzle.

Two distinct flow fields can be seen on the rear ventral duct wall (fig. 14). Near the tallpipe cutout, air that entered the duct opening from the downstream part of the tailpipe ( $\mathrm{fig}$. 10) set up a recirculation region revealed by the paint streaks aimed back to the cutout. This flow may have been weak because the paint collected on the sharp edge of the cutout. The recirculation was also seen in the velocity vector field computed by the PARC3D 
program (not shown here) and in the particle trajectories. The main flow, however, went directly along the wall toward the ventral nozzle.

Figure 15 shows the ventral nozzle, looking from the duct toward the exit. The paint streaks show that the air flowed straight through the nozzle except near the forward wall, where crossflow from the twin vortices described previously is clearly evident. These streaks indicate that the flow leaving the nozzle was not uniform and may still have contained nonaxial components, which detracted from nozzle total thrust.

Nozzle exit flow. - A flow-angle survey was made in the nozzle exit flow with a conventional conical probe (fig. $6(b)$ ) that had direction-sensing pressure ports. Although this survey was made at PR5 $=1.69$ (stream Mach number, 0.9 ) because the probe was not calibrated for supersonic flow, the results are indicative of the exit flow at higher pressure ratios. Two survey traverses at the exit plane were made: one near an outboard edge of the nozzle (fig. $16(a)$ ), and the other near the plane of symmetry (fig. $16(b)$ ). Near the outboard edge there was little or no pressure loss except near the forward nozzle lip. The flow direction was outboard and forward in the aft part of the nozzle and inboard and forward in the front part. Near the plane of symmetry the measured total pressure was as much as 15 percent less that the average station 5 pressure. The flow directions were similar to the directions nearer the outboard edge, but the flow angles were greater. The results show that the flow leaving the nozzle was still trying to "fill in" the lower-density region at the center of the upstream wall. Although not measured, mirror images of these patterns must exist on the other side of the plane of symmetry. On that basis, the yaw velocity components would cancel but cause a net thrust loss, but the axial components would remain and add to cause a net thrust in the reverse (downstream) direction. These data, then, corroborate and explain the axial force measured by the facility load cells, previously shown in figure 11 .

An additional survey of the nozzle exit flow was made with a rake that had three pressure-sensing tips ( $f i g .6(a)$ ). The data from this survey were processed into a pressure contour map at the exit plane, which is shown in figure 17 together with a similar map computed by the PARC30 code. As in some of the preceding figures, only one of the symmetric halves is shown. Results are given for $P R 5=3$. The analytical map always shows true total pressure, but the experimental data are pitot pressures, which are less than true total pressure by the normal shock loss at the tip in supersonic flow and by measurement errors when the flow angle relative to the tip was greater than about $15^{\circ}$. Nevertheless, the maps are in excellent agreement: both show strong flow in the rear part of the nozzle and an oval-shaped region of weaker flow in the front part.

\section{CONCLUDING REMARKS}

Experimental and analytical flow studies of the same generic model tailpipe and ventral nozzle have been made. The model was about one-third of full size, and the end was closed to simulate a blocked exhaust nozzle. Test data were obtained up to a ratio of tailpipe to ambient pressure of 4.0. The analytical work was done by using the PARC 30 computational fluid dynamics program on a Cray Y-MP computer to predict the internal flow patterns and overall ventral system performance. The major results of these studies are as follows: 
1. About 5\%-percent flow-turning total-pressure loss was measured in the model tested. This result is expected to be typical of full-size systems of similar geometry, but the loss should be lower for smaller ventral nozzles or systems with entrance flow-turning devices.

2. Ventral nozzle flow and thrust coefficlents were normal considering the measured flow-turning loss.

3. A reverse (directed downstream) thrust component was measured, al though the ventral nozzle axis was normal to the tallpipe centerline. This indicates that the flow turned more than the intended $90^{\circ}$.

4. Paint streak flow visualization photographs and other data showed that a low-density region of separated vortical flow occurred at the upstream wall of the ventral duct. Flow was strong in the downstream part of the duct and tended to move toward the upstream wall from both the side and rear walls. This pattern persisted through the nozzle exit and caused the axial component measured by the thrust system.

5. The modeling technique and the PARC3D computational code did a thoroughly capable job of analyzing internal flow patterns and predicting system performance. Analytical results were very similar to the flow visualization photographs and the exit plane pressure contour map, and the predicted thrust and flow coefficients were within 1 percent of the measured values.

\section{REFERENCES}

1. G. Raman, K.B.M.Q. Zaman, and E.J. Rice, "Initial Turbulence Effect on Jet Evolution With and Without Tonal Excitation," AIAA Paper 87-2725, October, 1987.

2. C.F. Smith and J.G. McArdle, "Analysis of the Internal Flow in a Ventral Nozzle for STOVL Aircraft," AIAA Paper 90-1899, July, 1990.

3. T.A. Wynosky, and C.J. Szyszko, "V/STOL Deflector Aerodynamic Design Criteria," AIAA Paper 73-1181, Nov. 1973.

4. B.M. Romine, Jr., B.E. Meyer, and R.J. Re, "A Static Investigation of Several STOVL Exhaust System Concepts," AIAA Paper 89-2928, July, 1989.

\begin{abstract}
Positione and opinions advanced in this paper are those of the author(s) and not necesarily those of SAE. The author is solely responsible for the content of the paper. A process is avallable by which discuselons will be printed with the paper if it is published in SAE Traneactions. For permission to publish this paper in full or in part, contact the SAE Publleations Divibion.
\end{abstract}

Persons wishing to submit papers to be considered for presentation or publlcation through SAE should send the manuscript or a 300 word abstract of a proposed manuscript to: Secretary, Engineering Actlvity Board, SAE. 


\section{ORIGINAL PAGE \\ BLACK AND WHITE PHOTOGRAPH}

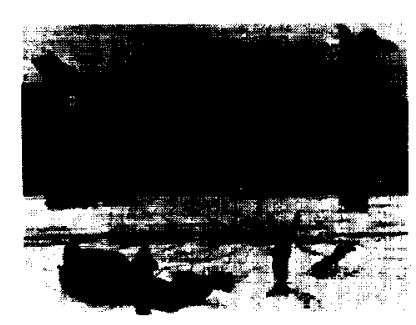

(a) EJECTOR AUGMENTOR.

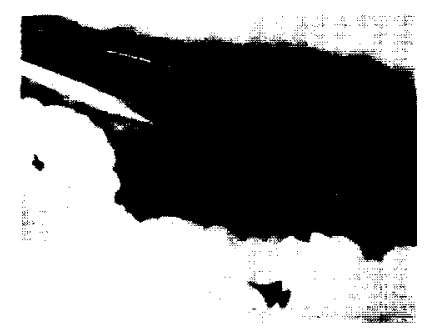

(c) MIXED-FLOW VECTORED THRUST.

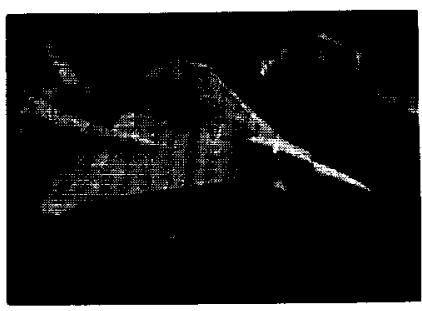

(b) REMOTE AUGMENTED-LIFT SYSTEM.

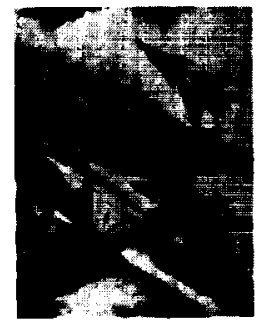

(d) HYBRID TANDEM

FIGURE 1. - CONCEPTUAL STOVL AIRCRAFT WITH VARIOUS PROPULSION SYSTEMS.

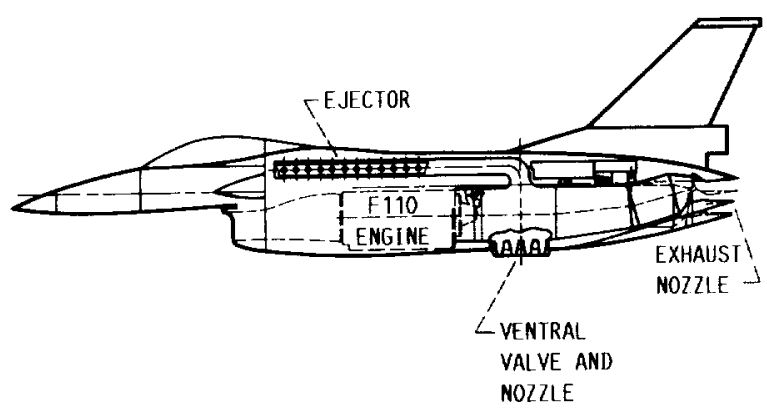

FIGURE 2. - PROPOSED STOVL PROPULSION SYSTEM WITH VENIRAI NOZZLE, ON ETD AIRCRAFT MODEL. 
BLACK AND VIHITE PHOTOGRATM

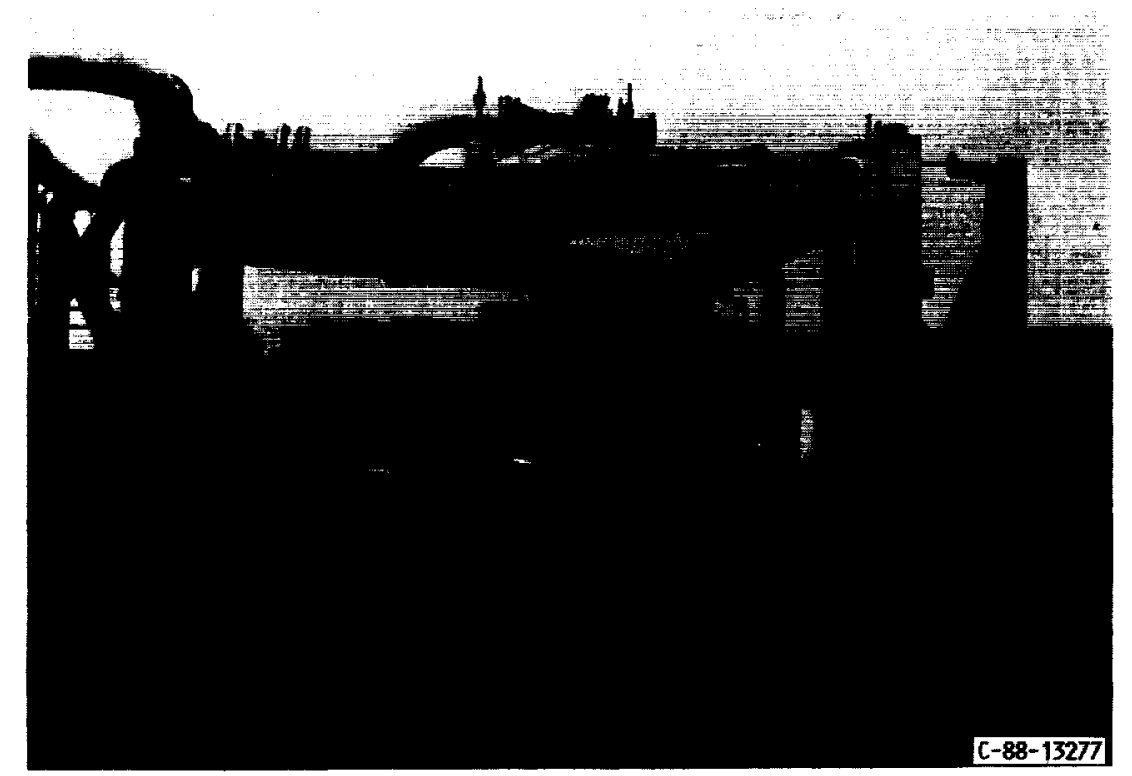

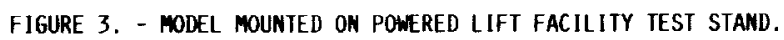

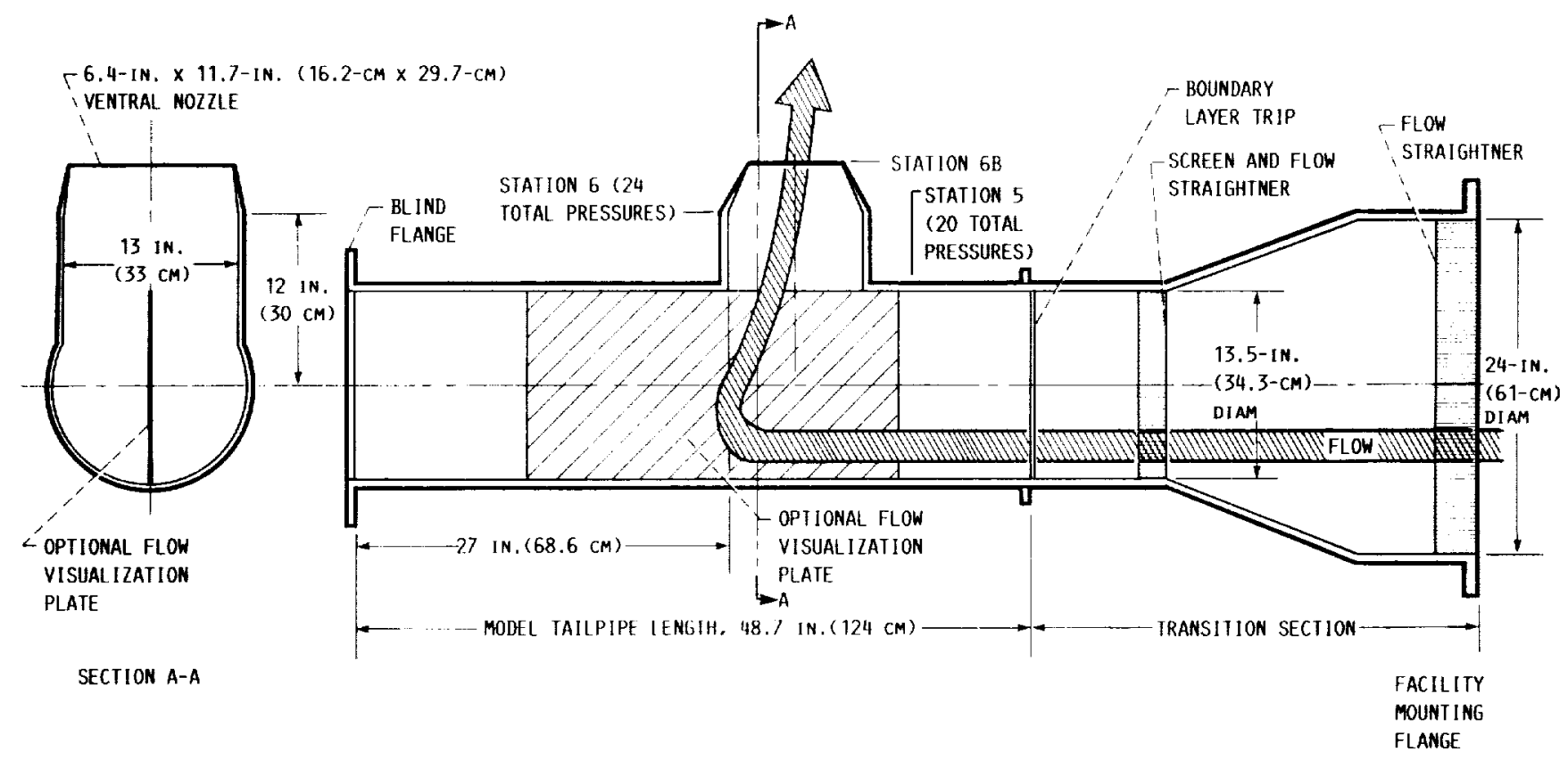

FIGURE 4. - EXPERIMENIAL MODEL OF TAILPIPE/NENTRAL NOZZLE. 


\section{BLACK AND WHITE FHOTOGRAPH}

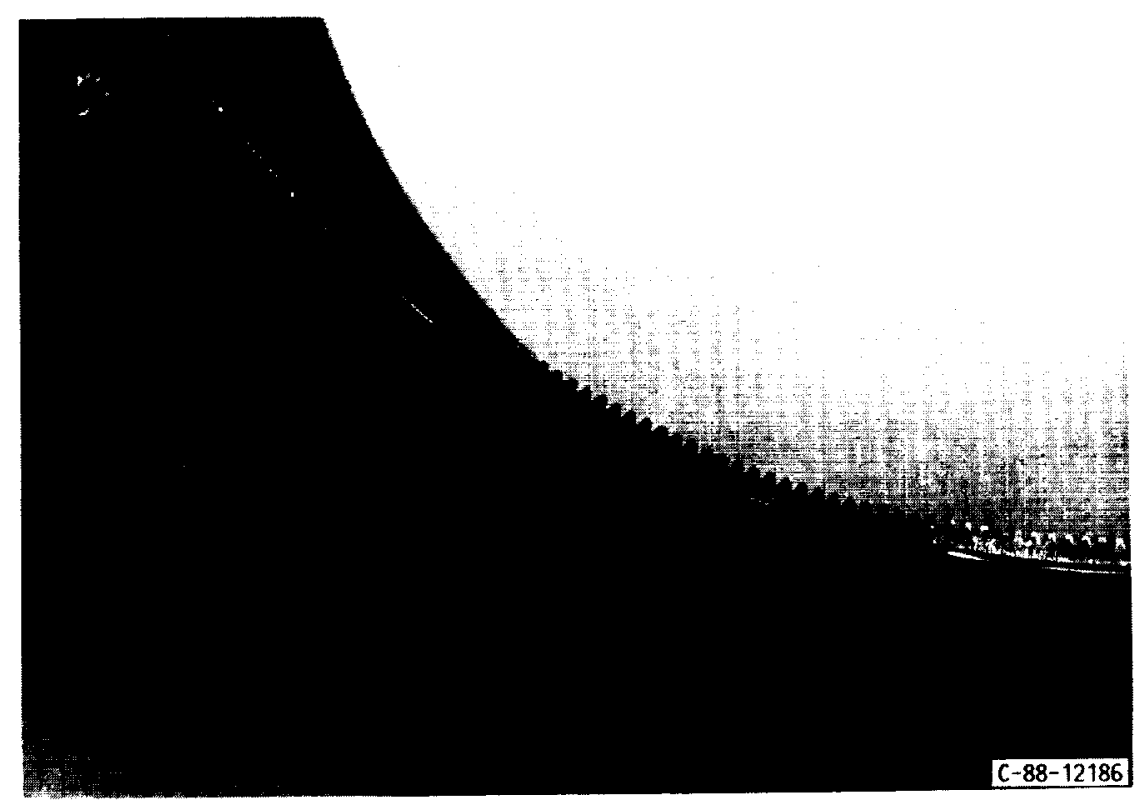

FIGURE 5. - BOUNDARY LAYER TRIP IN EXPERIMENTAL MODEL.
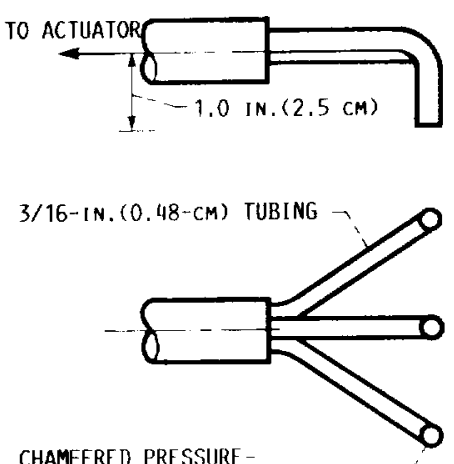

CHAMFERED PRESSURE-

SENSING TIP, TYPICAL 3 PLACES -

\begin{abstract}
(a) THREE-TIPPED PROBE TO MEASURE PITOT PRESSURE.
\end{abstract}

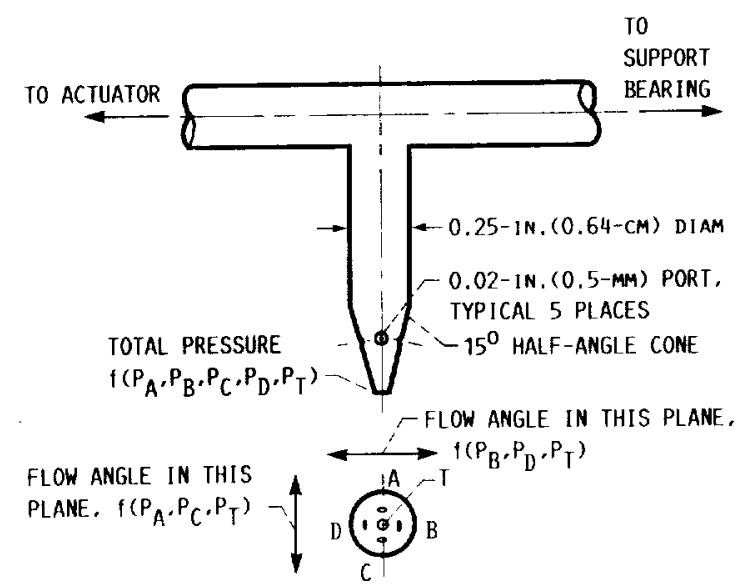

(b) FIVE-PORT CONICAL PROBE. THE PROBE WAS CALIBRATED TO MEASURE FLOW ANGLES AND TRUE TOTAL PRESSURE AT FLOW ANGLES UP TO $\pm 30^{\circ}$.

FIGURE 6. - PROBES USED TO STUDY VENTRAL NOZZLE EXIT FLOW. 


\author{
ORIGINAL FRIXE \\ BLACK AND WHITE PHOTOGRAPH
}

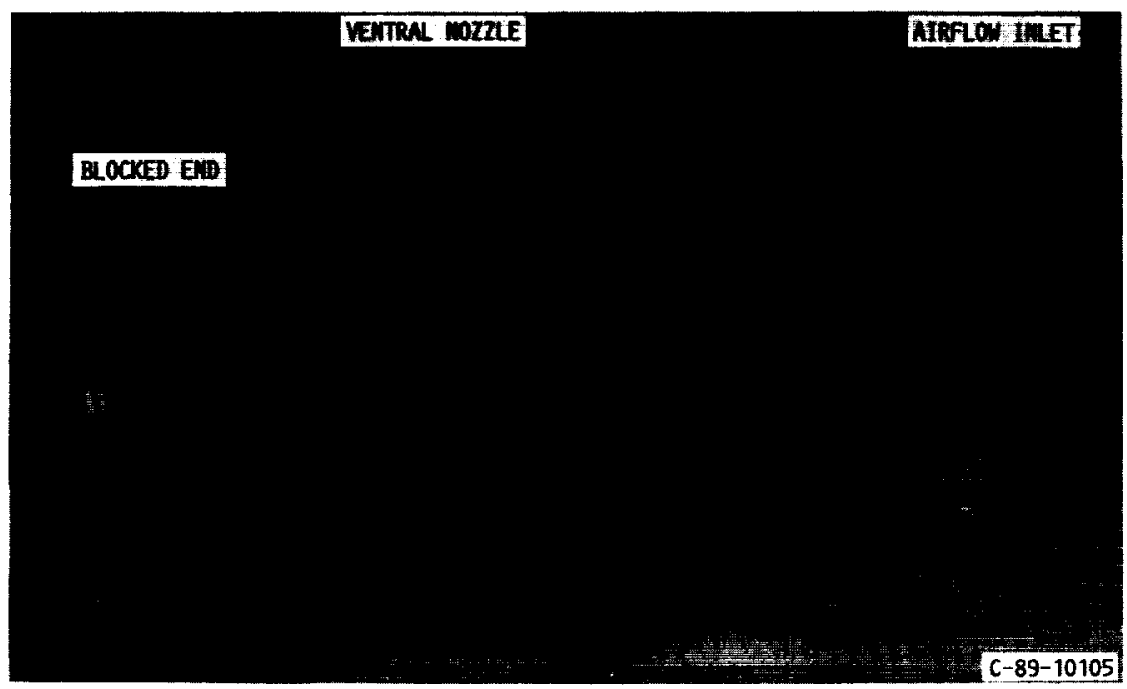

(a) EXPERIMENTAL MODEL.

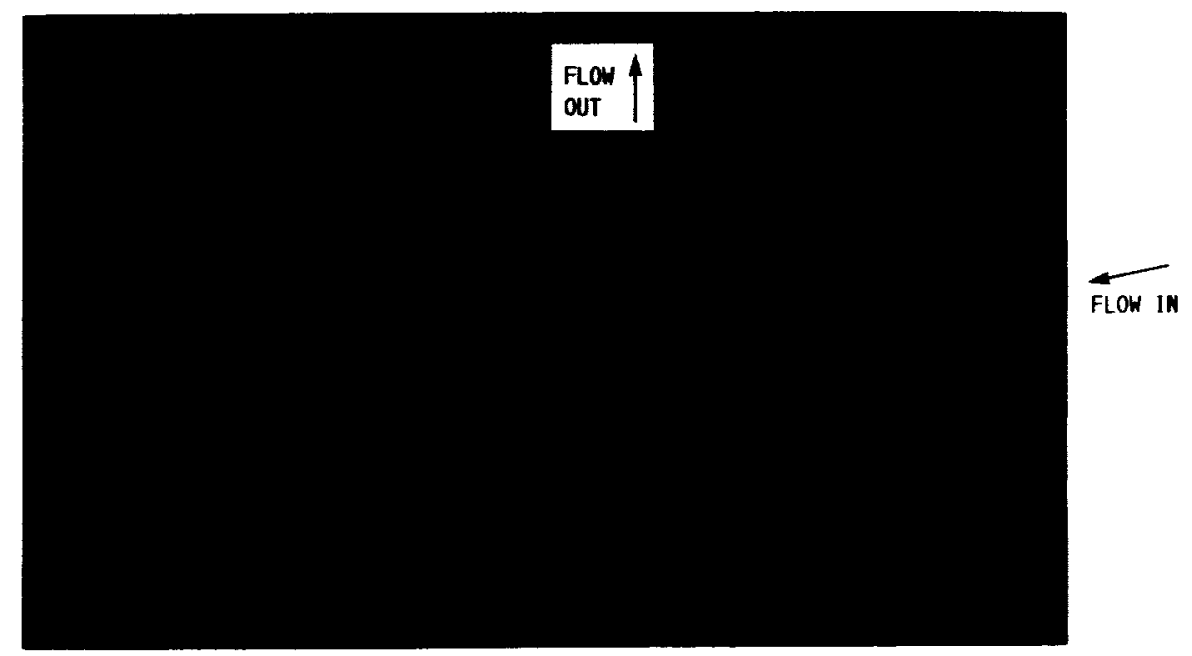

(b) ANALYIICAL "WIRE" DIAGRAM. (ONLY ONE-HALF IS USED FOR CFD; FOR CLARITY, MANY OF THE GRID LINES ARE NOT SHOWN.)

FIGURE 7. - VENTRAL SYSTEM CONFIGURATION. 


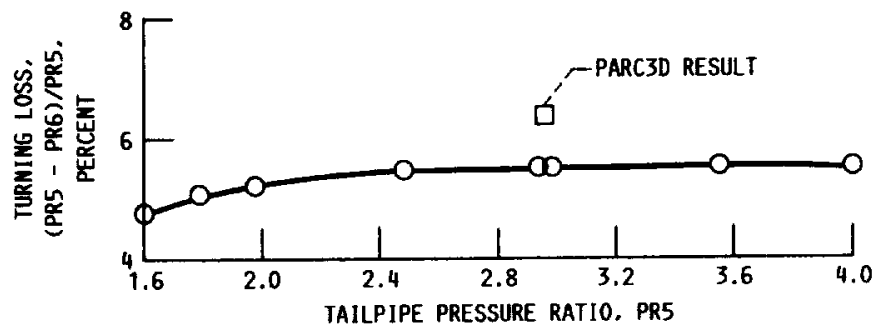

FIGURE 8. - TOTAL-PRESSURE FLON-TURNING LOSS.

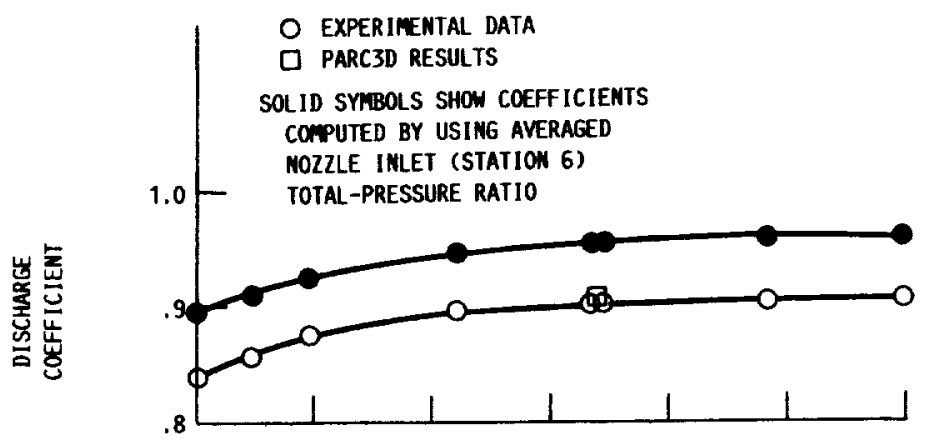

(a) DISCHARGE COEFFICIEMT,

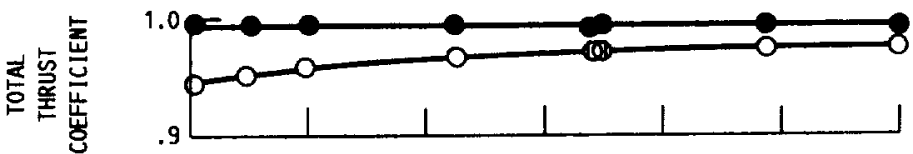

(b) THRUST COEFFICIENT.

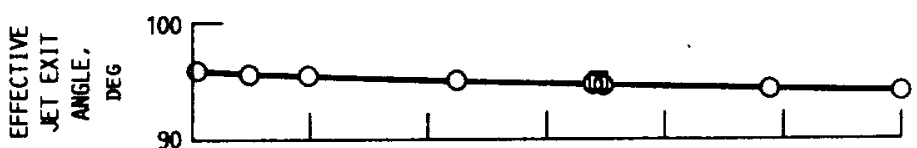

(c) JET AMGLE.

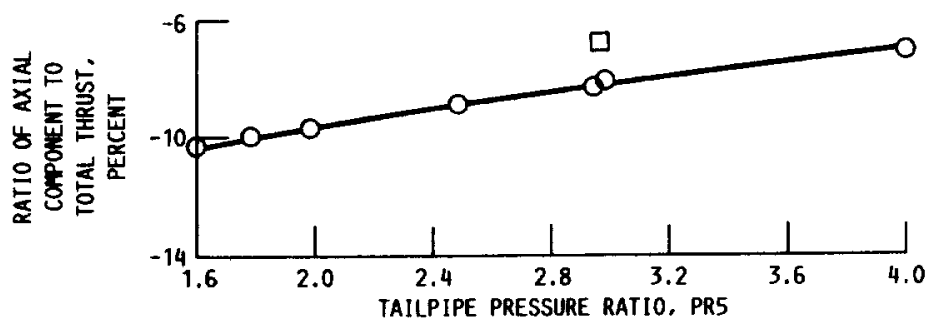

(d) AXIAL FORCE COMPONENT.

Figure 9. - Ventral SYSTEM PERFormance. 


\section{ORIGINAL PACEE \\ BLACK AND WHITE PHOTOGRATH}

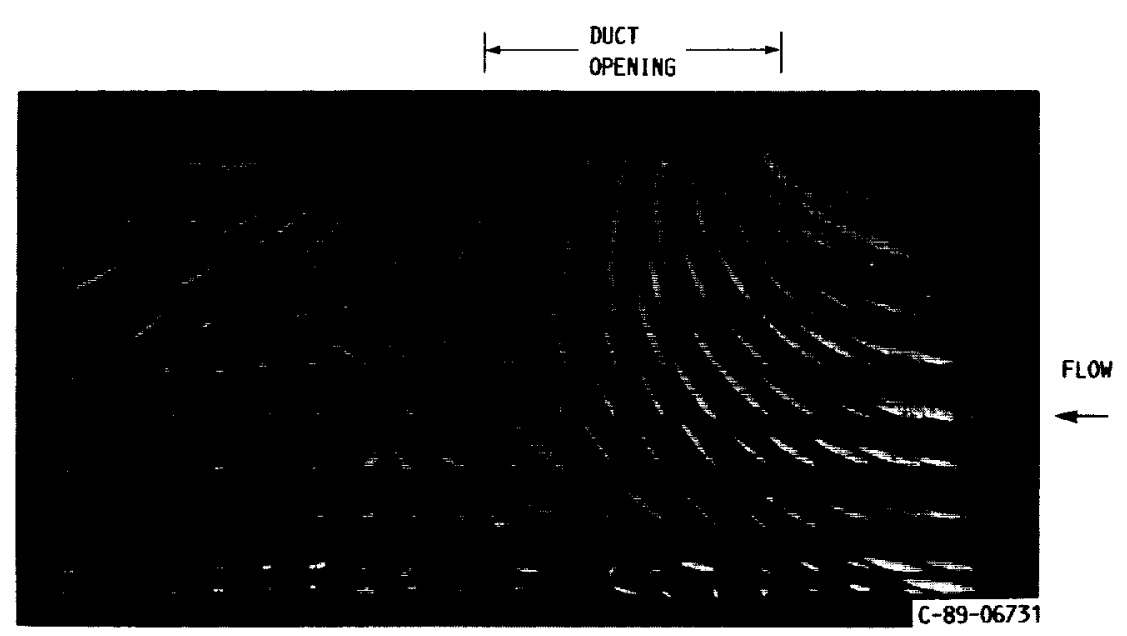

(a) FLON VISUALIZATION PLATE AT VENTRAL NOZZLE INLET.

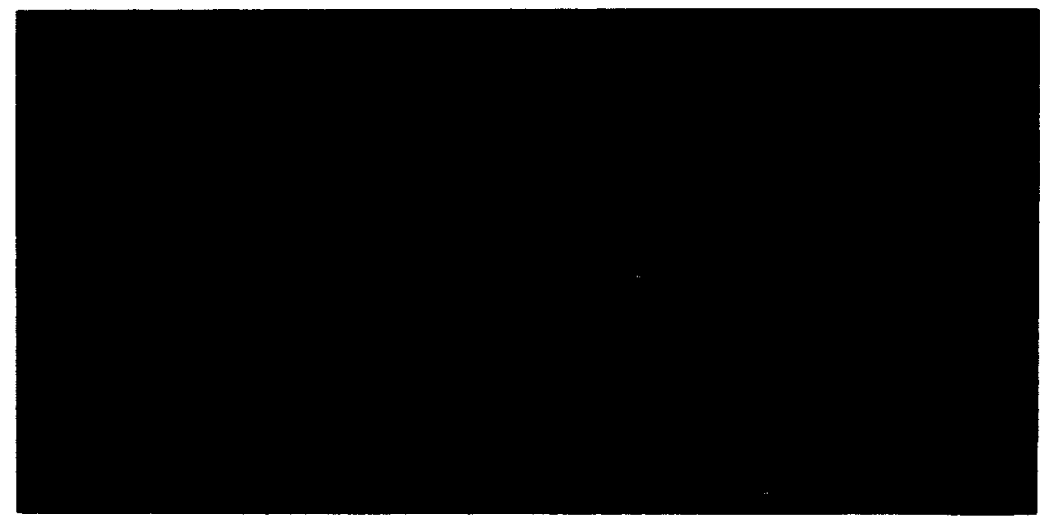

(b) VELOCITY VECTOR FIELD ON TAILPIPE PLANE OF SYMMETRY, COMPUTED BY PARC3D CODE. FIGURE 10. - FLOW PATTERNS ENTERING VENTRAL DUCT. 

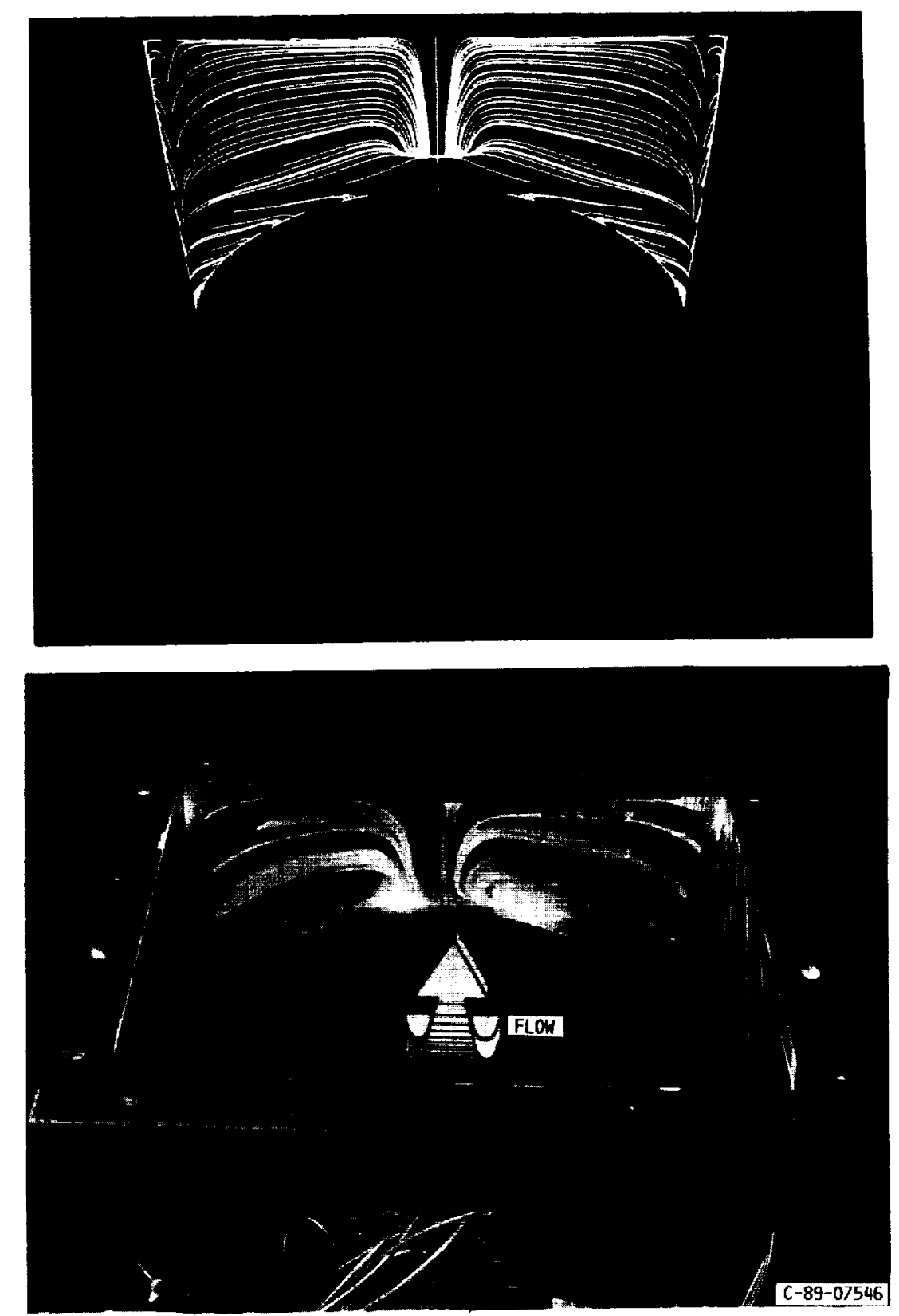

FIGURE 11. - FLOW VISUALIZATION ON VENTRAL DUCT FRONT WALL.

\section{ORIGINAL PATE}

BLACK AND WHITE PHOTOGRAPH 


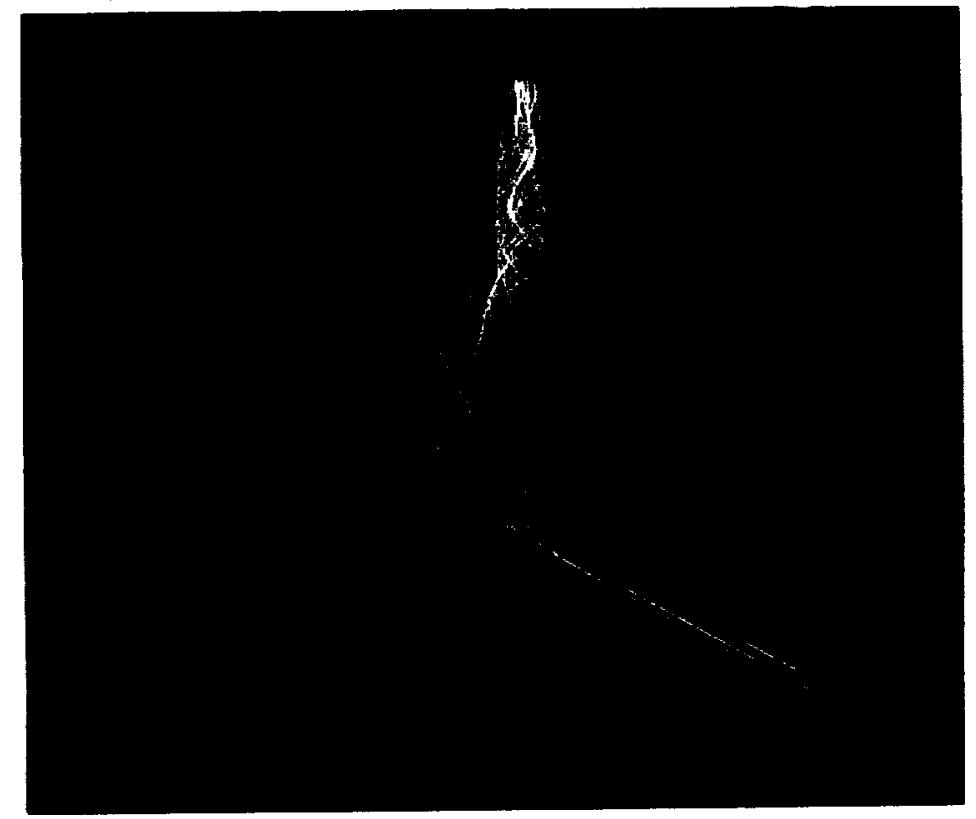

FIGURE 12. - PARTICLE TRAJECTORY SHOWING VORTEX FLOW NEAR UPSTREAM VENTRAL DUCT WALL. 

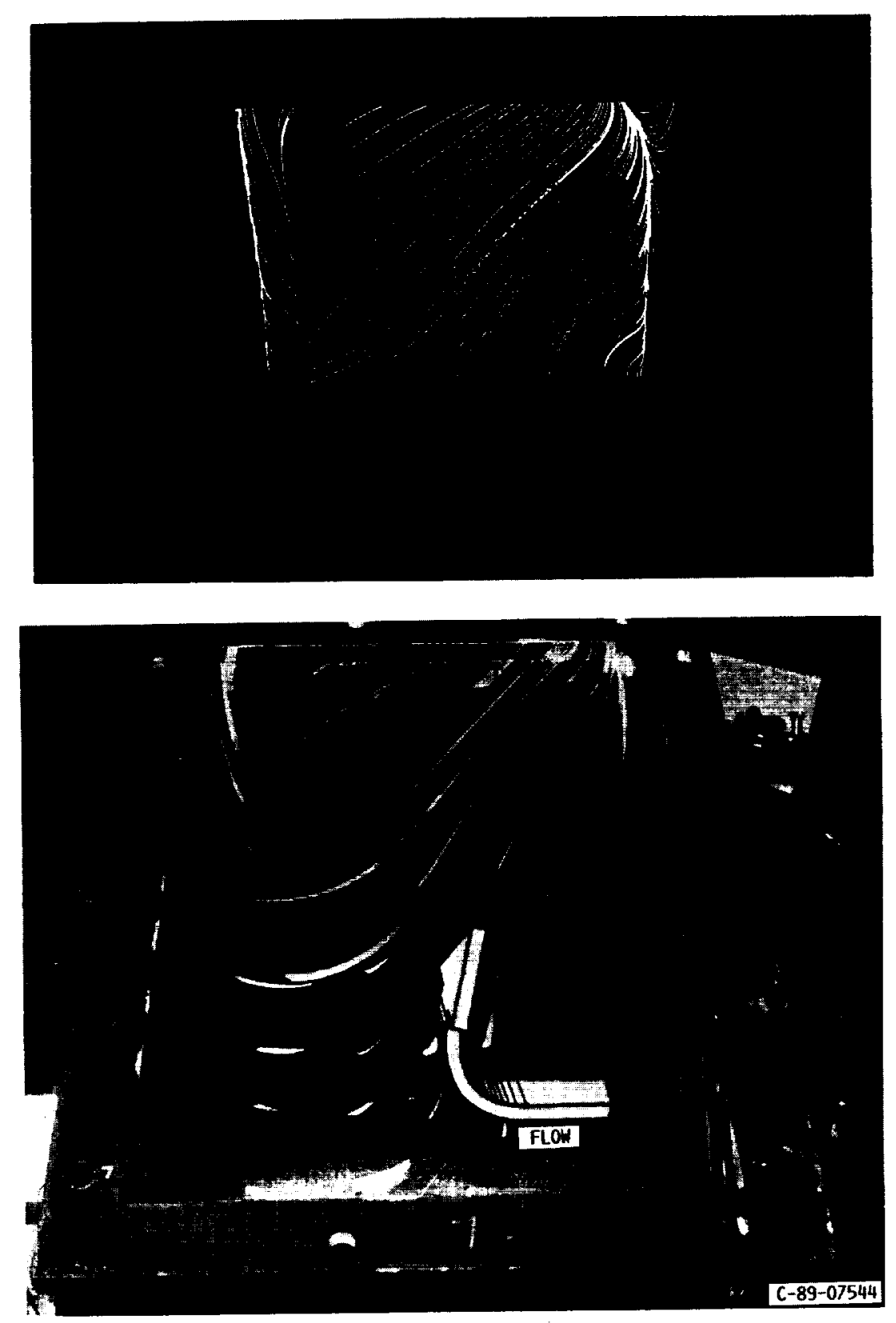

FIGURE 13. - FLOW VISUALIZATION OH VENTRAL DUCT SIDE WALL.

ORIGINAL PAGE

BLACK AND WHITE PHOTOGRAPH 

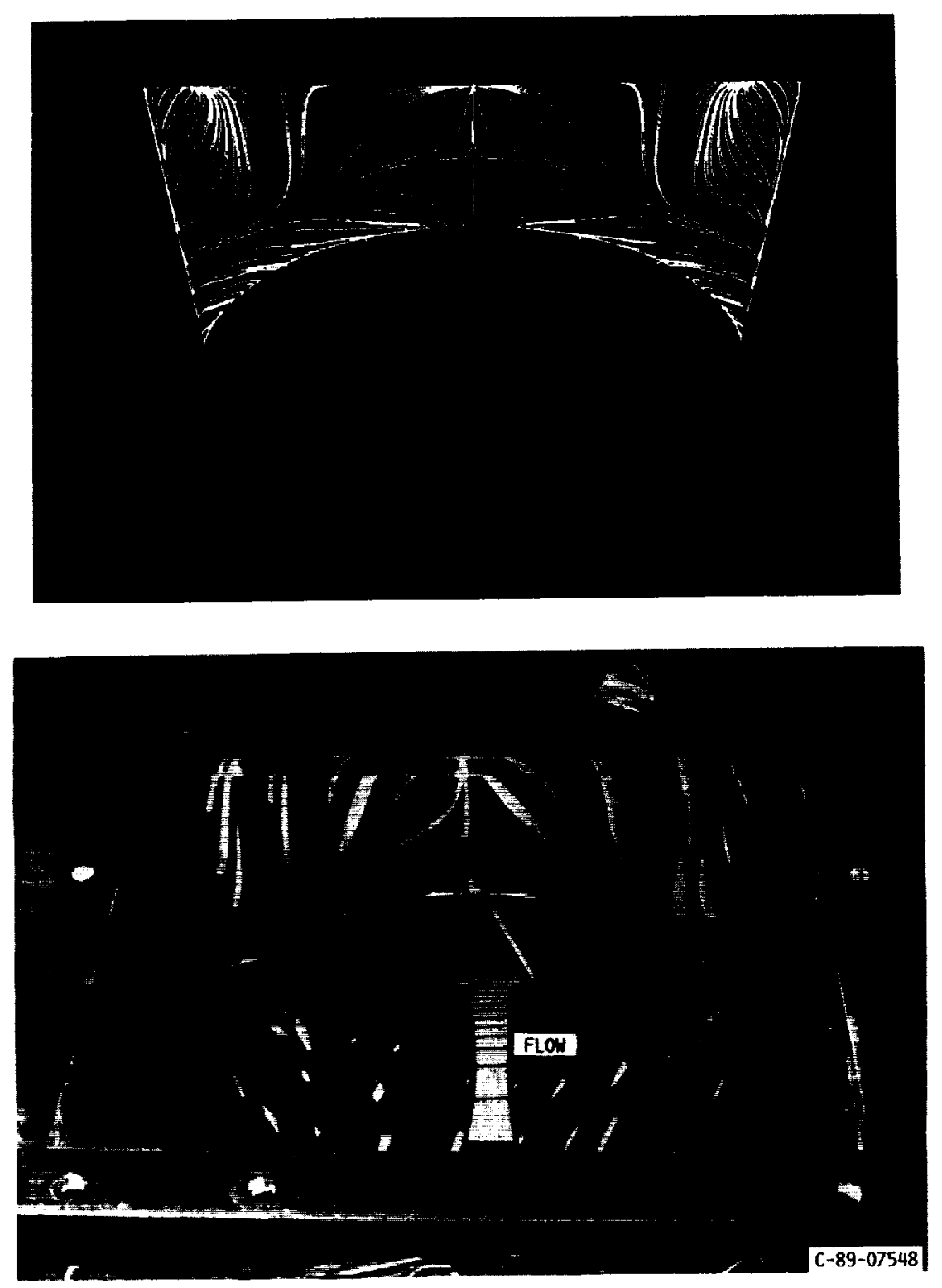

FIGURE 14. - FLOW VISUALIZATION ON VENTRAL DUCT DOWNSTREAM WALL.

ORIGINAL FRGE

BLACK AND WHITE FHOIOGRAPH 


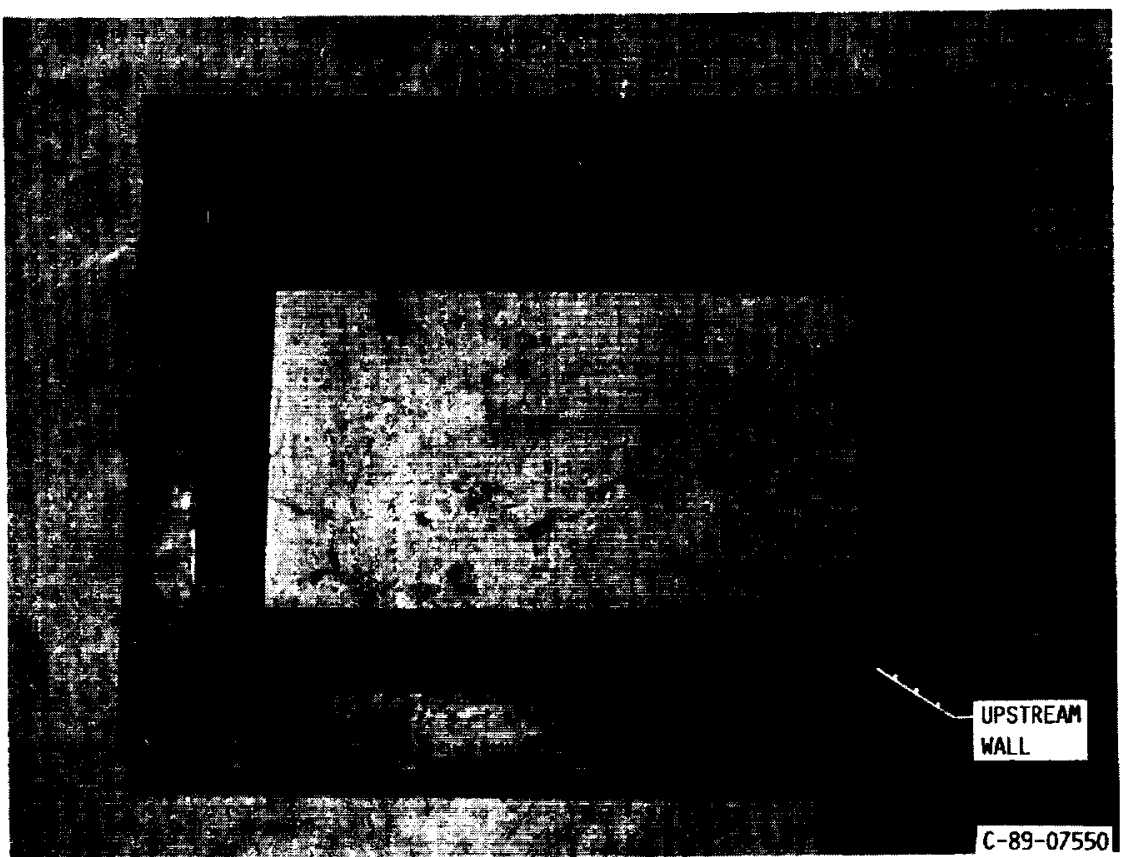

FIgURE 15. - PAINT STREAK FLOW VISUAL IZATION ON VENTRAL NOZZLE. VIEW LOOKING FROM DUCT TOWARD NOZZLE EXIT.
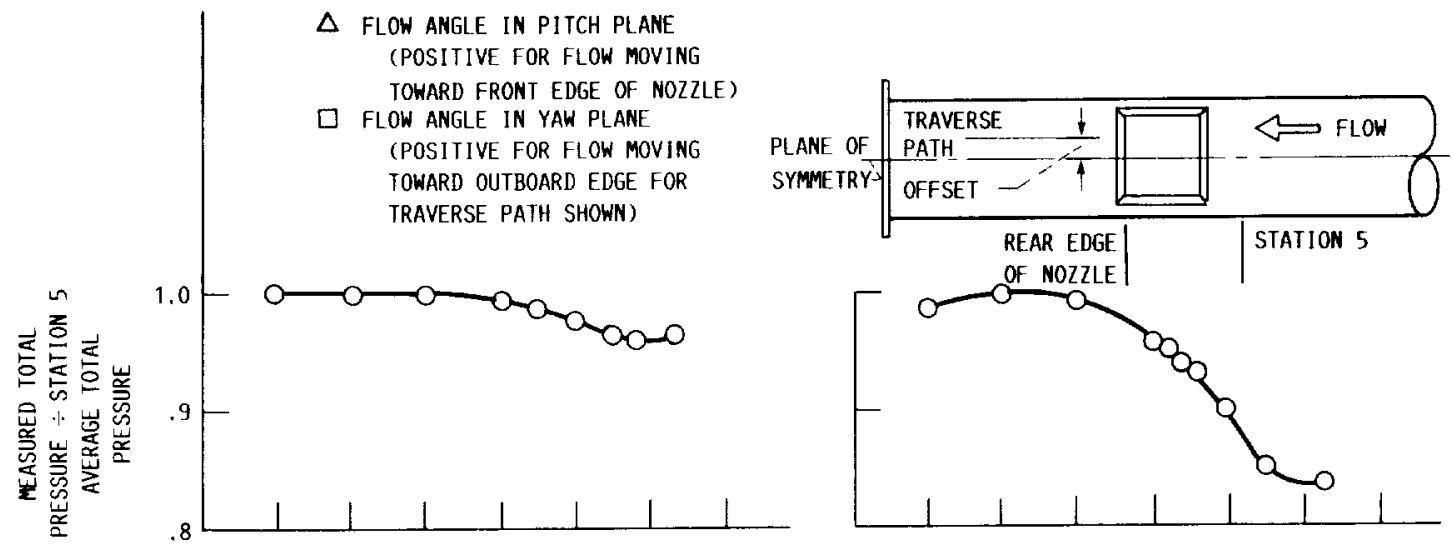

通
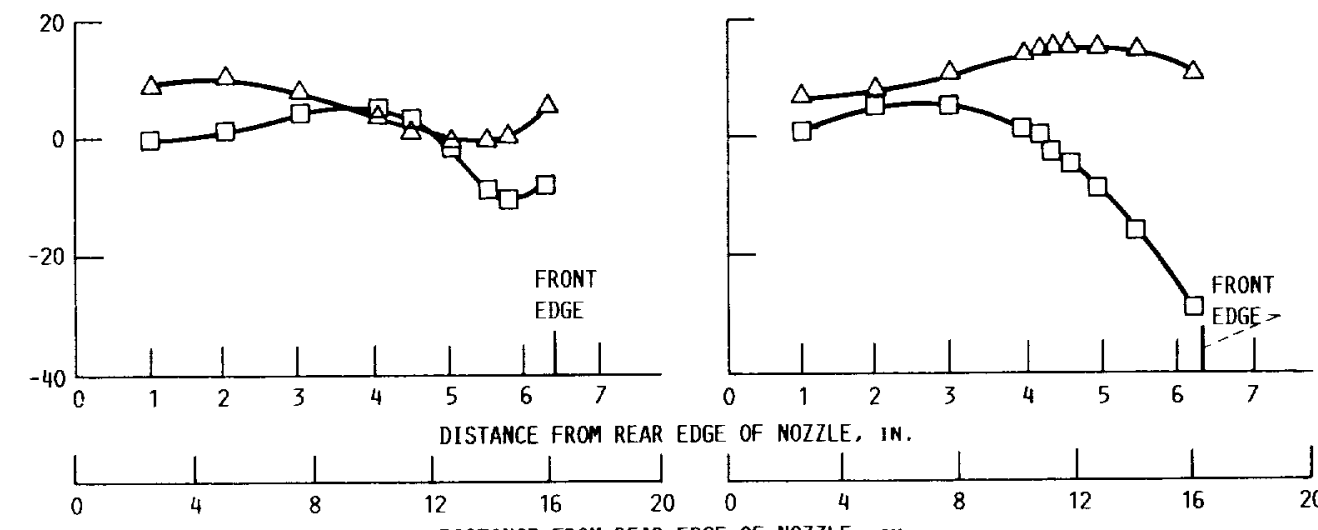

DGE OF NOZZLE, IN.

DISIANCE FROM REAR EDGE OF NOZZLE， CM

(a) TRAVERSE PATH OFFSET 4.5 IN. (11.4 CM) FROM PLANE OF SYMMETRY. (b) TRAVERSE PATH OFFSET $1.5 \mathrm{IN} .(3.8 \mathrm{~cm})$ FROM PLANE OF SYMMETRY.

FiguRE 16. - VENTRAL NOZZLE EXIT FLOW CONDITIONS. RATIO OF TAILPIPE TO AMBIENT PRESSURE, PR5. 1.69. 


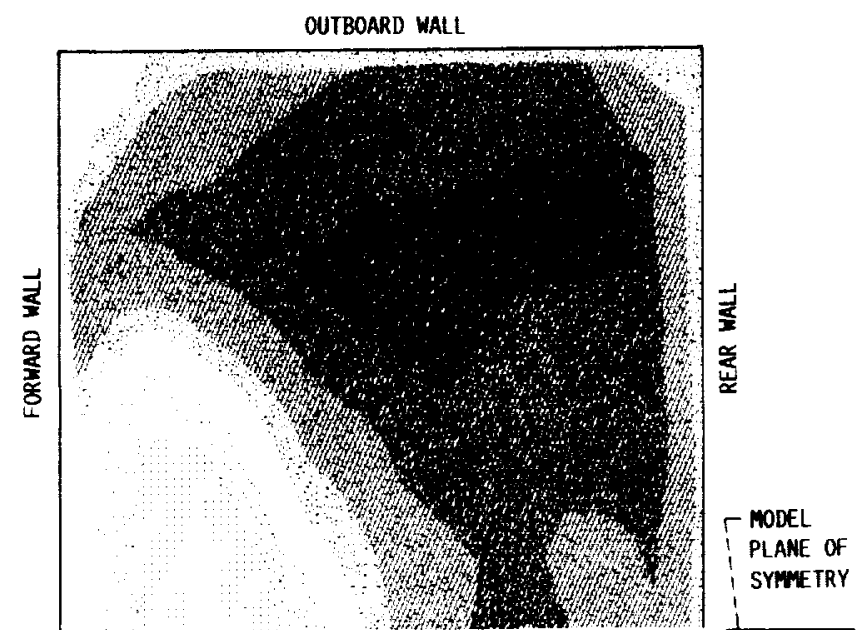

(a) EXPERIMENTAL PITOT PRESSURE.

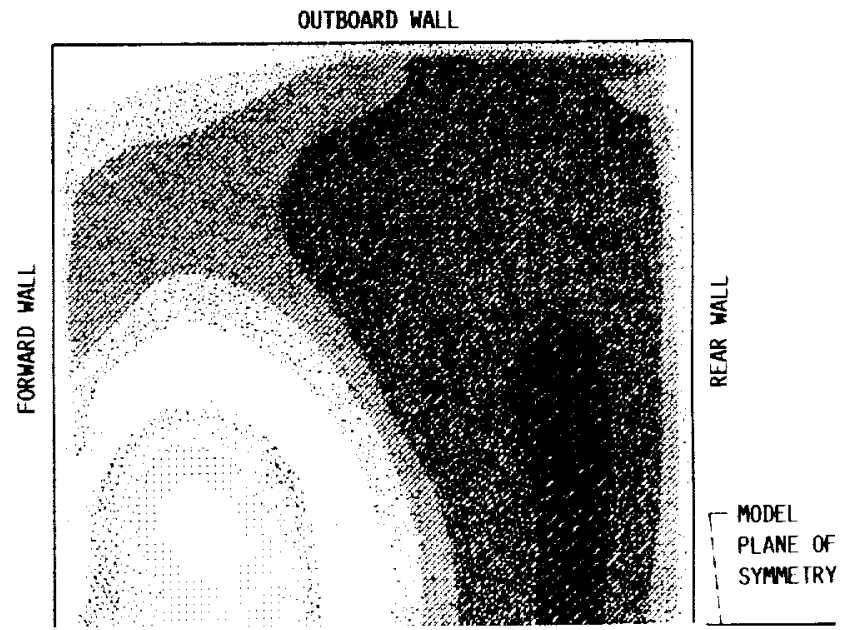

(b) AMALYTICAL TOTAL PRESSURE.

FIGURE 17. - NOZZLE EXIT PLANE PRESSURE CONTOUnS. LIGHT SHADINGS INDICATE LOWER PRESSURES. DARK SHADINGS INDICATE HIGHER PRESSURES. 



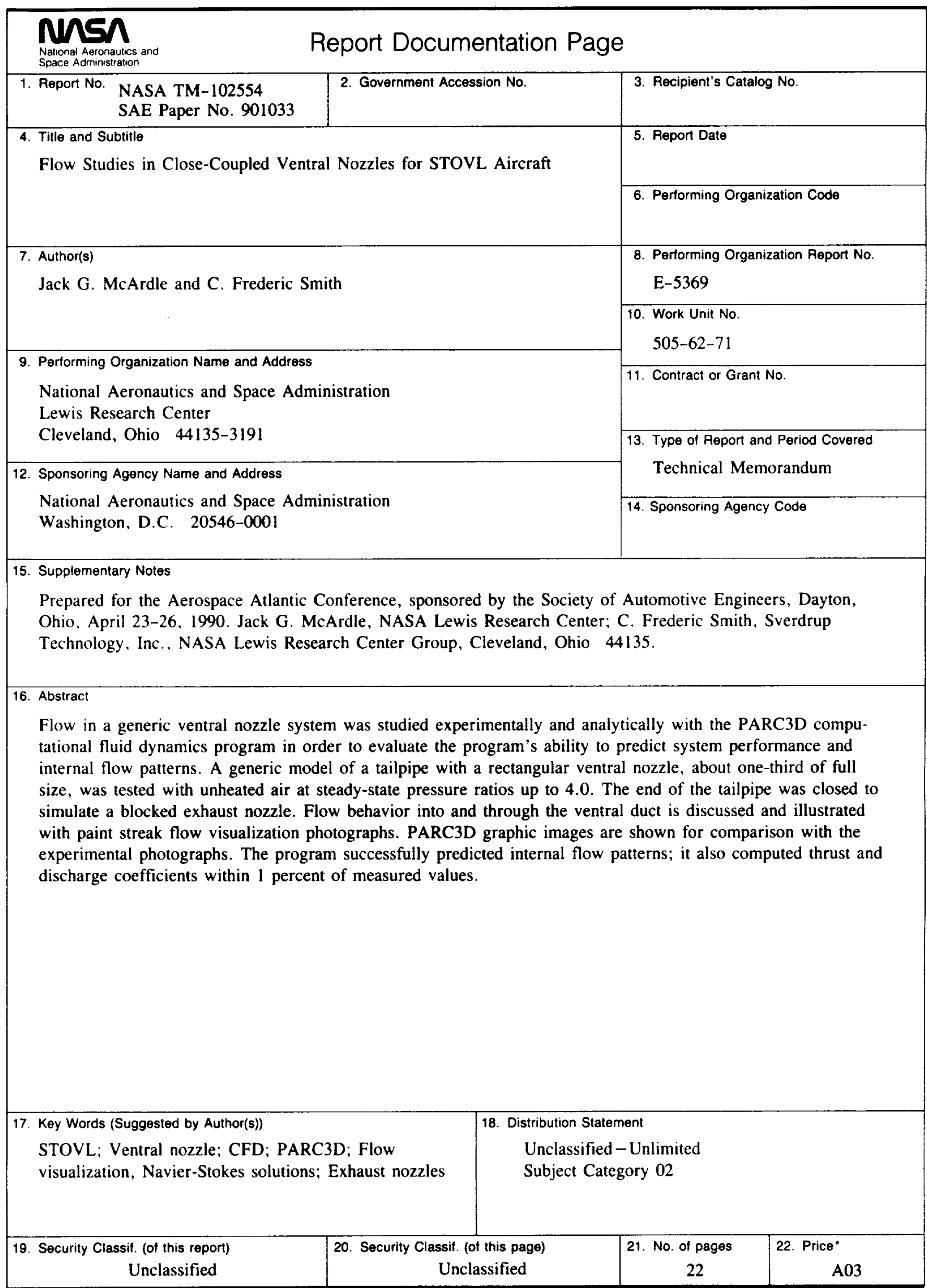





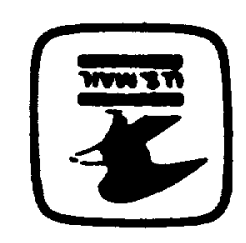

a $15 \exists$ ก
SEItt 0140 ' puejanalo selues 40jeasoy s!me7

uo!̣e pue solneuosar jeuo!leN 